\title{
EDITORIAL
}

\section{Editorial: The World Coming Out of Its Shell}

\author{
Stephen Scypinski ${ }^{1}$
}

Published online: 25 May 2021

(c) The Author(s), under exclusive licence to Springer Science+Business Media, LLC, part of Springer Nature 2021

Dear Readers of the Journal of Pharmaceutical Innovation,

Since I last wrote to you in March, a great deal has happened. Many of us in the USA have been fully vaccinated against COVID-19; a multitude of states and countries are in the various stages of returning to normal, and, most recently, a new guidance by the Center for Disease Control (CDC) here in the USA allows fully vaccinated individuals to cease wearing masks. This is all good news yet, unfortunately, it is not the same around the world. Many colleagues in countries such as India and Japan are still living and trying to work in the throes of the ongoing pandemic. I know I speak for my editors and other staff of the journal when I say I hope the situation improves in these areas very soon.

Yet, despite the ongoing pandemic, innovation in the pharmaceutical industry continues to thrive; throughout the last 15 months, I have been continually amazed at the number of manuscripts being received by this journal that attest to the cutting-edge research and development being performed in both industry and academia. Consider this, the June 2021 issue in the pages following this editorial. Innovative approaches to drug delivery continue to be a hot topic, being fueled by the complexity of the therapeutic agents being administered. Manuscripts in this issue explore nanocarriers, microsponges, and microspheres as examples of techniques on the horizon. Other topics in this issue include a discussion of operating patterns in pharmaceutical quality control laboratories and an article on hydrogen peroxide decontamination in aseptic processing. I am sure that, as you peruse either the online or hard copies of this issue of the Journal of Pharmaceutical Innovation, you will find articles of interest that may even spark additional work in your laboratories.

As we literally and figuratively close the books on another issue of this journal, I want to thank all the contributors and readers who support JOPI and help it thrive and grow. As I have stated it, this is YOUR journal and as such fosters an open dialog with its readers and subscribers. If you have any suggestions, comments, and even criticisms, I want to hear from you. My email address is sscypinski@comcast. net. Until our next issue, stay safe and well.

Publisher's Note Springer Nature remains neutral with regard to jurisdictional claims in published maps and institutional affiliations.

The statements contained herein are my personal views and opinions and are not those of my employer.

Stephen Scypinski

sscypinski@comcast.net

1 Daiichi-Sankyo Inc., Basking Ridge, NJ 07920, USA 